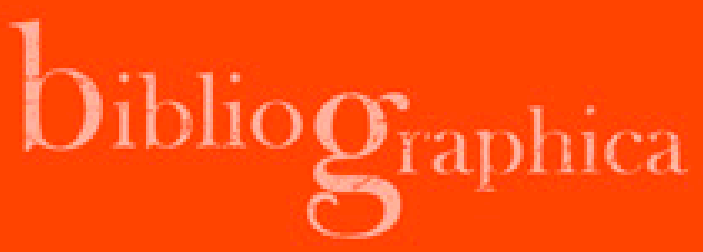

\title{
La obra literaria abierta: del soporte digital al impreso
}

Susana Patricia Ruiz Espinosa. México: Bonilla Artigas Editores / Tecnológico de Monterrey / Conacyt, 2016, 248 pp. ISBN: 978-607-8450-30-5

\section{Dalia Valdez Garza}

Universidad Nacional Autónoma de México Instituto de Investigaciones Bibliográficas

Recepción 18.01.18 / Aceptación 24.01.18

DOI: https://doi.org/10.22201/iib.bibliographica.2018.1.15 
[La literatura] sólo vive si se propone objetivos desmesurados, incluso más allá de toda posibilidad de realización.

Ítalo Calvino

Poner en evidencia los modos en que un productor literario (autor) se sirve de las tecnologías de producción de textos -o de otros elementos extra textuales como los gráficos, icónicos o sonoros- y brindar una herramienta de análisis con el posicionamiento del consumidor (lector) de estos productos como coconstructor o incluso postproductor de las obras, es sólo parte de lo que Susana Ruiz hace en La obra literaria abierta: del soporte digital al impreso. Esta idea es además el planteamiento eje en los distintos ejercicios que realiza, entre los que están la recapitulación de teorías y términos, la propuesta de un modelo y su aplicación, su reflexión crítica sobre tecnología y literatura y un glosario de términos. De principio a fin la autora retoma ideas de otros autores, a la vez que amplía el panorama en un campo para el cual hacía falta brindar no sólo claridad conceptual, sino una propuesta original de análisis de obras literarias a la luz de las teorías previas y posteriores a la revolución del texto electrónico (Roger Chartier).

El despliegue teórico-conceptual de la primera parte de la obra, producto de un recorrido por los "estudios realizados en torno al fenómeno literario con soporte electrónico", para los que Ruiz asigna la categoría de teoría literaria digital -de Espen J. Aarseth, N. Katherine Hayles, Laura Borràs y Belén Gache, entre otros-, sienta unas bases firmes en la construcción de una propuesta útil y original de modelo para el análisis de cierto tipo de obra literaria que es vista siempre en relación con un lector que recupera sus elementos con la mente (que interpreta) y el cuerpo (con el que accede físicamente) para darle sentidos múltiples, reversibles, ideales o descentrados. En el diseño de este modelo la autora hizo no solamente una hábil abstracción de ideas halladas en la teoría sobre literatura digital que se vuelcan moldeadas hacia los requerimientos de análisis de un tipo particular de obra, sino de las de otros escritores y teóricos de una literatura impresa como Roland Barthes, Julia Kristeva, Jacques Derrida, Gilles Deleuze, Félix Guattari y Umberto Eco.

Es precisamente de Eco de quien toma el término de obra abierta para referirse al tipo de obra literaria que será susceptible de análisis bajo su propuesta de modelo y que, en síntesis, es posible entender como una constelación de elementos en la obra cuya realización da pie a recorridos o lecturas múltiples. En este concierto teórico, la propuesta de estudio de la literatura bajo la óptica del entendimiento de una obra como abierta, promueve una nueva y ampliada serie de consideraciones para el análisis de obras de realización en soporte indistinto, derivada de lo que la teoría para la literatura electrónica pudo revelar como lo que en principio pareció ser propio de la tecnología de la cual derivaba. De este modo, a lo largo del libro se dan ejemplos de estrategias (como la hipertextualidad) en las cuales queda clara la dilución de las fronteras que la tecnología parecería enfatizar como diferenciadoras en la producción textual impresa en relación con la digital, pues ese es el enfoque 
que la autora requiere dar a su propuesta para abarcar los dos ámbitos.

La caracterización que hace Ruiz bajo el término de obra abierta de Eco se sostiene en un sólido marco conceptual donde se insertan y concatenan en su definición planteamientos de Milorad Pavić (obra literaria reversible), Belén Gache (formas escriturarias nomades), Roland Barthes (texto ideal), del mismo Eco y otros, con lo cual insiste en resaltar la pluralidad de recorridos, perspectivas o derivas en la lectura. El productor de una obra literaria abierta aprovecha la cualidad activa, productiva y colaborativa del lector ante un texto que le da la posibilidad de tomar algunas decisiones a las que el autor da pie, sin que con ello se anulen las posibilidades de sentido sino que, al contrario, se potencializan. Por ejemplo, como explica la autora, un rasgo de la obra abierta es que el lector puede acceder a ella desde distintos puntos, a tal grado que puede llegar a borrarse la concepción tradicional de inicio y final -lo que llama "descentralización de la obra" por su espacio-, o bien tener la opción de elegir finales diversos, entre otras estrategias de construcción textual, para posibilitar la generación de sentidos múltiples. Esto en cuanto a las opciones de tipo interpretativo que el lector puede tomar, pero también, como destaca Ruiz, las hay físicas, como las que derivan de la solicitud de un orden de lectura aparentemente arbitrario que rompe con el hojear sucesivo según el número de página, o de enfrentarse a formas y estructuras que demandan un movimiento ocular que rompe con la linealidad tradicional o con la habitual forma (distancia o postura) de colocar el libro.
Pero, ¿le queda al concepto de "libro" un lugar en estas reflexiones, considerando que ha sido el instrumento por el que más se ha vehiculizado la textualidad literaria a lo largo de la historia? Sí, y no sólo en el subapartado final sobre el futuro de los libros, sino a lo largo de toda la obra, implícitamente cuando se habla de los soportes y, en particular, aunque no siempre se hace evidente, en el primer aspecto del modelo de análisis: la materialidad. Dentro de los cuatro elementos del modelo de análisis para las obras literarias abiertas (materialidad, estructura, textualidad y sentido) que convergen en la figura del lector, es el primero el que evoca la idea del libro. Ruiz considera que mediante el análisis de la materialidad es posible aproximarse al objeto en el cual se lee y a la identificación de las posibilidades que el tipo de soporte le da al contenido para su despliegue. Y si bien por tratarse de un análisis literario el enfoque se da en esta relación del soporte con el contenido por ser además lo que da pauta a distintas formas de lectura, es evidente que dicho "objeto" al cual hace referencia la autora es lo que se llama "libro".

Pero Ruiz hace referencia no solamente a un "objeto", sino a un "aparato" o dispositivo de lectura, con lo cual podría entenderse -y vale la pena aclararlo desde la perspectiva de los estudios del libro, por ser complementaria- que independientemente de si se habla de un soporte para texto impreso -materiales tangibles como el papel-o digital, en realidad puede hacerse referencia al "libro" como "tecnología" impresa o digital que, en el caso de la segunda, se reproduce en "dispositivos" como computadoras, tabletas o celulares. En 
cambio, el libro como tecnología impresa es en sí mismo un dispositivo de lectura. En el caso de la literatura, al perseguir "objetivos desmesurados", según lo plantea Ítalo Calvino, es posible que sus productores abandonen en algunos casos el paradigma del libro como propuesta objetual, e incluso los soportes tradicionales de las textualidades impresa y digital, con planteamientos de una materialidad más efímera, por ejemplo, como respuesta no solamente a la necesidad de nuevos posicionamientos estéticos del artista frente a la sociedad, sino también a su búsqueda de una nueva relación con el público. Serán finalmente los lectores quienes decidirán a qué productos literarios seguir llamando "libros", e indagarlo y registrarlo corresponderá a los campos de la historia de las ideas y de la historia del libro.

Por lo pronto, en la perspectiva de estudio de la literatura como obra abierta, a pesar de la idea evocada de libro en una lectura desde una tradicional visión de la literatura, no se debe perder de vista que se trata con "artefactos literarios" (como los Ilama Hayles) irreductibles a una sola posibilidad de realización estructural y material que hoy todavía se relaciona con la idea de libro. Justamente el ejercicio de trabajar con este modelo puede dar pie a la categorización de nuevos géneros textuales y editoriales en el ámbito de la literatura, representados en una versión evolucionada de libro -quizá híbrida e innovadora en relación con sus componentes intelectuales y físicos, internos y externos, textuales y extra textuales, tangibles e intangibles, orgánicos e inorgánicos, perecederos e imperecederos, técnicos y artísticos- que además pondría cada vez más en evidencia la necesidad de abarcar, en un análisis integral, el elemento que la teoría de la literatura de base impresa había dejado a un lado: la materialidad como parte de la propuesta estética del autor.

El libro podría entenderse -en la línea de los planteamientos de Ruiz- ciertamente en calidad de objeto, pero también como tecnología tangible o intangible (materialidad) compuesta de páginas en las cuales se concreta la textualidad a partir de una estructura, mientras que los aparatos que le sirven de plataforma al libro también son tecnología tangible que permite diversas representaciones de textualidad gracias a otro tipo de tecnología, esta vez intangible, como es el software. La producción textual (del autor, o del lector como postproductor de la obra) requiere entonces de una intermediación material para su despliegue en una sola ejecución (en papel y fija, entendida en términos de una edición) o sobre la base de aparatos que permiten su despliegue en distintas ejecuciones fijas o variables, en ambos casos, con posibilidades de descentralización del texto o de hipertextualidad, por mencionar dos estrategias. Éste es un ejemplo de cómo el modelo de Ruiz aporta elementos de reflexión que pueden llevarse a los estudios del libro y ser aclaratorios, al traerse de vuelta a la explicación del modelo. Y quizá esto sea así en gran medida porque al final la literatura es, junto con la bibliografía, la disciplina que más ha colaborado con la historia del libro, en un intento de explicarlo en toda su complejidad a partir de distintas dimensiones que, en el caso de la literatura, 
es principalmente la textual pero que, como se ha visto, hoy por hoy es indisociable de la material. En este sentido las aportaciones de Ruiz pueden servir de puente de conexión entre disciplinas como las mencionadas y todas verse enriquecidas -como creo que pueden serlo- con el diálogo que ella ya ha propiciado no casualmente entre las ideas de Roger Chartier y Katherine Hayles, sobre cómo las formas de los textos y sus soportes son determinantes en los procesos de generación de sentido y comprensión lectora.

Otro punto de paralelo interdisciplinario entre la literatura, a través del modelo de Ruiz, y la historia del libro es el relacionado con el segundo aspecto del modelo: la estructura. Nuevamente, centrada en el ámbito de su interés que es la obra literaria abierta, en su modelo señala el elemento de "estructura" como parte de lo que guía al lector hacia una u otra forma de sentido, a partir de elementos organizadores en el texto o formas que, tanto en literatura como en la historia del libro, se les ha denominado "paratextos" para su estudio (aunque no son sólo éstos los que Ruiz considera). Cabe mencionar que el historiador del libro Robert Darnton ha hecho explícita la importancia del tema de los paratextos para la disciplina. Pero, a diferencia de la historia del libro que toma en cuenta los aspectos legales y económicos, entre otros, que inciden en la producción y características de estos elementos estructurales llamados paratextos y varían según la época y el lugar, en el caso del modelo para la obra literaria abierta el análisis se centra, según explica la autora, en el modo de relación entre la estructura externa u organización del texto y la estructura de la trama.

Todo, en fin, en el modelo de análisis que propone Ruiz está basado en la perspectiva del lector y la textualidad no podía ser la excepción, lo cual merece una última reflexión. Se trata de un tipo de análisis literario en que no se ha partido de la textualidad, sino que para interpretarla se han establecido previamente una serie de relaciones con otros elementos de la obra, no menos o más importantes porque no se plantean de ese modo, sino como necesarios para la comprensión cabal de una obra que cumple con las características de ser abierta. Aquí la autora se sirve de los conceptos de intertextualidad (también reconocido como aspecto importante para abordar en la historia de libro por parte de Darnton) y de la hipertextualidad, en tanto relaciones evocadas o físicas presentes en el texto, respectivamente. Es el punto también donde Ruiz plantea una cuestión fundamental: "¿la hipertextualidad está en el texto o en el lector?", a lo cual podría responderse que está latente en el texto y sólo se realiza gracias al lector, es decir, cuando él opta por recorrer el camino mediante las conexiones que establece el autor; pero no es esto lo más relevante, sino resaltar que, de principio a fin de esta obra, y principalmente en el modelo, con todos sus elementos, la autora hace hincapié en la definición de obra abierta en relación con las posibilidades de decisión y acción de cada lector. Los resultados de este tipo de análisis, como puede verificarse en los casos de aplicación que ella misma presenta -Juego 
OD de cartas de Max Aub, Nocilla dream de Agustín Fernández Mayo y Beside myself de Jeff Gomez- brindarán a futuro un material valioso para campos como la historia del autor, del lector y de la tecnología en la creación de obras y elaboración de libros, y en este sentido la aportación de Ruiz trasciende su propia disciplina que es la literatura, gracias a una visión integral, reflexiva y visionaria de la obra literaria y de lo que todavía hoy es el libro. 